\title{
Mixing of fluids with dissimilar viscosities in Confined Impinging Jets
}

DOI:

10.1016/j.cherd.2018.04.020

\section{Document Version}

Accepted author manuscript

Link to publication record in Manchester Research Explorer

\section{Citation for published version (APA):}

Brito, M. S. C. A., Esteves, L. P., Fonte, C. P., Dias, M. M., Lopes, J. C. B., \& Santos, R. J. (2018). Mixing of fluids with dissimilar viscosities in Confined Impinging Jets. Chemical Engineering Research and Design, 134, 392-404. https://doi.org/10.1016/j.cherd.2018.04.020

\section{Published in:}

Chemical Engineering Research and Design

\section{Citing this paper}

Please note that where the full-text provided on Manchester Research Explorer is the Author Accepted Manuscript or Proof version this may differ from the final Published version. If citing, it is advised that you check and use the publisher's definitive version.

\section{General rights}

Copyright and moral rights for the publications made accessible in the Research Explorer are retained by the authors and/or other copyright owners and it is a condition of accessing publications that users recognise and abide by the legal requirements associated with these rights.

\section{Takedown policy}

If you believe that this document breaches copyright please refer to the University of Manchester's Takedown Procedures [http://man.ac.uk/04Y6Bo] or contact uml.scholarlycommunications@manchester.ac.uk providing relevant details, so we can investigate your claim.

\section{OPEN ACCESS}




\title{
Mixing of fluids with dissimilar viscosities in Confined Impinging Jets
}

\author{
M.S.C.A. Brito ${ }^{1}$, L.P. Esteves ${ }^{1}$, C.P. Fonte ${ }^{2}$, M.M. Dias ${ }^{1}$, J.C.B. Lopes ${ }^{1}$, \\ R.J. Santos ${ }^{1}$ \\ ${ }^{1}$ Laboratory of Separation and Reaction Engineering - Laboratory of Catalysis and \\ Materials (LSRE-LCM), Faculdade de Engenharia, Universidade do Porto, Rua Dr. Roberto \\ Frias, 4200-465 Porto, Portugal \\ ${ }^{2}$ School of Chemical Engineering and Analytical Science, The University of Manchester, \\ Oxford Road, Manchester M13 9PL, U.K.
}

\section{Introduction}

Confined Impinging Jets (CIJs) are highly efficient mixing devices composed of a semi-confined mixing chamber with two directly opposed injectors near the closed top of the chamber and an open end from where the fluids exit the device (Lee et al. 1980, Tucker and Suh 1980, Wood et al. 1991, Johnson et al. 1996, Johnson 2000a, Johnson 2000b, Johnson and Wood 2000, Santos and Sultan 2013). The fluids enter into the mixing chamber through two round opposed injectors, with diameter in the millimetre range, as high-speed opposed jets with velocities in the range $1 \mathrm{~m} / \mathrm{s}$ to $100 \mathrm{~m} / \mathrm{s}$. The mixing chamber is typically a cylinder whose diameter is much larger than the inlet diameters causing a strong dissipation and large increase of the interfacial contact area.

When the fluids are fed to the mixing chamber through the injectors, there is a radial spread of fluid upon the jets impingement point that forms a 3D squeezed fluid structure occupying the diameter of the mixing chamber, resembling a pancake as described by Wood et al. (1991). For balanced flow conditions between opposed jets (same diameter, flow rate and fluid) this pancake like flow structure is centred at the intersection of the mixing chamber and injectors axis and depending on the jets Reynolds number can be steady or evolve dynamically. At low jets Reynolds numbers, less than 100, the interface between the two opposed fluids is fixed at the mixing chamber axis and the mixing scale corresponds to half the mixing chamber diameter, $D / 2$, while for larger Reynolds numbers chaotic flow regimes are observed (Santos et al. 2010, Santos and Sultan 2013).

The onset of chaotic flow regimes decreases the mixing scales in ClJs around two orders of magnitude, from $D / 2$ to $D / 200$ (Fonte et al. 2011, Santos and Sultan 2013). The operation at chaotic flow regimes is thus a necessary condition for ClJs efficient operation and the jets Reynolds number has been known from early works to be a key parameter (Malguarnera and Suh 1977, Lee et al. 1980, Tucker and Suh 1980). Operation above the critical Reynolds number is achieved at high flow rates, which for viscosity values above $1 \mathrm{~Pa} \cdot \mathrm{s}$ and in industrial settings require the use of technologies such as rotary piston pumps. The other parameter that plays a critical role regarding operation at chaotic flow regimes is balancing the two jets, which was clearly demonstrated by Fonte et al. (2015). Later an elastic analogue model was proposed to describe the mechanics for equilibrium between two opposed jets (Fonte et al. 2016), which was validated in the case of mixing of similar fluids, i.e. having same viscosity and density.

ClJs most common application is on reactive polymerization, namely the Reaction Injection Moulding (RIM) process. In the RIM process two reactive monomers are injected one from each jet, often with different flow rates since the monomers must be mixed at stoichiometric ratio, with flow rate ratios between $1: 1$ to $1: 2$. When the jets flow rate ratio differs more than $10 \%$ from $1: 1$, even for similar fluids mixing, the jets are not balanced and mixing is compromised, as shown by Fonte et al. (2015). This limitation is overcome by using two opposite injectors with different diameters, in a relation 
that has been proven to be well-described by the elastic analogue model. RIM poses yet another problem for the most efficient use of $\mathrm{ClJs}$, since the monomers have different viscosities, for example, for polyurethane production, isocyanate has a viscosity in the $0.1 \mathrm{~Pa} \cdot \mathrm{s}$ range, and polyols around $1 \mathrm{~Pa} \cdot \mathrm{s}$. State-of-the-art RIM machines deal with these reactive polymers formulations by using ClJs where the jets are not directly opposite, promoting circulation patterns around the impingement point, but failing to use the full power of the jets on the generation of interfacial area at the jets impingement point.

This work studies mixing of dissimilar fluids, namely with different viscosities, in CIJs using PLIF experimental data and CFD simulations, for conditions typical of those used in industrial applications. A full characterization of dissimilar fluids mixing in $\mathrm{ClJs}$ is presented showing that the equilibrium of the jets impingement point position is a necessary condition to onset chaotic mixing in RIM. The elastic analogue model, previously validated for similar fluids (Fonte et al. 2016), is applied and validated for dissimilar fluids, enabling the design of ClJs with directly opposed jets impinging at mixing chamber axis for fluids with different viscosities.

Chaotic flow regimes, which are the regimes of operation of industrial application, have been previously observed only for operation of CIJs with opposed jets with the same fluid and equal flow rates, i.e. symmetric CIJs conditions. This work shows the ability to operate at chaotic flow regimes with dissimilar fluids, and identifies the respective critical Reynolds number marking the onset of chaotic regimes.

\section{CIJs CFD model}

The ClJs used in this work have typical dimensions of those used in industrial RIM machines, see Figure 1. These ClJs consist on a semi-confined cylinder with height $H=50 \mathrm{~mm}$, diameter $D=$ $10 \mathrm{~mm}$, and two cylindrical opposed injectors with diameter $d=1.5 \mathrm{~mm}$ placed at $h=5 \mathrm{~mm}$ from the closed top of the mixing chamber. The injectors intersect the mixing chamber perpendicularly, and the inlet of the pipes is located at $7.5 \mathrm{~mm}$ from the mixing chamber axis. A parabolic velocity profile, normal to each injector, is defined for each inlet as

$$
v(r)=2 v_{i n j}\left(1-4 \frac{r^{2}}{d^{2}}\right)
$$

where $r$ is the distance from the injector axis, $v_{i n j}$ is the average velocity at the inlet and $d$ is the diameter of the injector. At the CIJs walls no slip conditions were set, and at the outlet a uniform value was set for the pressure. Two fluids were defined, one with viscosity $\mu_{1}=0.04 \mathrm{~Pa} \cdot \mathrm{s}$ and density $\rho_{1}=1000 \mathrm{~kg} / \mathrm{m}^{3}$, and the other with viscosity $\mu_{2}=0.02 \mathrm{~Pa} \cdot \mathrm{s}$ and density $\rho_{2}=$ $1000 \mathrm{~kg} / \mathrm{m}^{3}$. The CIJs geometry was discretised with a mesh of $2 \times 10^{6}$ nodes. The mesh cells are predominantly hexahedral.

The flow was simulated using the Finite Volume software package ANSYS/Fluent to solve the continuity equation,

$$
\boldsymbol{\nabla} \cdot \mathbf{u}=0
$$

and the Navier-Stokes equation,

$$
\rho \frac{\mathrm{Du}}{\mathrm{D} t}=-\nabla p+\mu \boldsymbol{\nabla}^{2} \mathbf{u}
$$

where $p$ is the pressure and $\mathbf{u}$ is the velocity vector. In addition, since two fluids were considered, mass transfer was also simulated using the equation, 


$$
\frac{\mathbf{D} C_{A}}{\mathbf{D} t}=\mathcal{D}_{A B} \nabla^{2} C_{A}
$$

where $C$ is the concentration of species $A$, in this case $A$ being fluid 1 or 2 , and $\mathcal{D}_{A B}$ is the diffusivity; in the CFD simulations $\mathcal{D}_{A B}=10^{-9} \mathrm{~m}^{2} / \mathrm{s}$ was used.

For the flow simulation a pressure-based solver was used, with the SIMPLEC pressure-velocity coupling scheme. For the spatial discretization second order UPWIND was used, and the simulations were performed for steady state.

\section{CIJs experimental setup}

Experiments were run in an acrylic ClJs mixer having the same dimensions of the CFD model shown in Figure 1. The flow dispensing system is composed of two lines each feeding one injector. Each line has a gear pump with a variable speed motor, a Coriolis flow meter, and a needle valve for fine tuning of the flow rate. Figure 2 shows the scheme of experimental setup as described in previous works (Santos et al. 2008, Fonte et al. 2015), with a photo of the flow dispensing setup with tanks and flow meters, Figure $2 \mathrm{a}$, and a photo of the acrylic CIJs mixer with the respective discharging chamber, Figure $2 b$.

Planar Laser Induced Fluorescence is used to characterize the flow field in the CIJs. In PLIF a laser sheet illuminates a plane within the flow of a fluid doped with a fluorescent dye. The fluorescent dye emits at a different wavelength from the laser, and an image of the flow is obtained filtering the laser wavelength, so the PLIF image maps the tracer in the laser sheet plane. The laser sheet was generated in a Nd:YAG laser with an emission peak at $532 \mathrm{~nm}$, and the tracer compound was Rhodamine $6 \mathrm{G}$ that has the maximum absorption of light close to $526 \mathrm{~nm}$ and emits fluorescence at $564 \mathrm{~nm}$. The PLIF images were acquired with a light glass filter $(545 \mathrm{~nm})$ in front of the digital camera.

The main difference from previous visualization works was the use of two dissimilar fluids. Both fluids are aqueous solutions of glycerol. Fluid 1 is an aqueous solution with $68 \%$ glycerol (mass concentration) with viscosity $\mu=0.02 \mathrm{~Pa} \cdot \mathrm{s}$, density $\rho=1176 \mathrm{~kg} / \mathrm{m}^{3}$ and refraction index 1.428 at $25{ }^{\circ} \mathrm{C}$. Fluid 2 is an aqueous solution with $80 \%$ glycerol (mass concentration) with viscosity $\mu=$ $0.04 \mathrm{~Pa} \cdot \mathrm{s}$, density $\rho=1208 \mathrm{~kg} / \mathrm{m}^{3}$ and refraction index 1.445 at $25^{\circ} \mathrm{C}$. The differences in refraction index cause diffraction of the laser light sheet when crossing the interface between the two fluids, which makes images obtained with these fluids unusable for the purpose of flow characterization. To overcome this limitation, the refraction index of the Fluid 1 was changed with food grade calcium chloride at a concentration of $187 \mathrm{~g} / \mathrm{L}$ to match the refraction index of Fluid 2 .

\section{Elastic analogue model description}

The jets Reynolds number, defined by Malguarnera and Suh (1977) as

$$
R e=\frac{\rho d v_{i n j}}{\mu}
$$

is known from the first studies of mixing on CIJs to be the critical parameter for mixing in RIM (Lee et al. 1980, Tucker and Suh 1980).

Figure 3 shows PLIF images of CIJs for equal injectors mixing of two similar fluids at equal flow rates, symmetric ClJs conditions, for Reynolds numbers ranging from 100 to 304. Fluid dyed with Rhodamine is injected from the right side and from the left side a white jet corresponding to clear fluid is seen. It is quite clear the existence of a critical Reynolds number at $R e \approx 110$ marking a flow regime transition from steady to chaotic. Steady flow regimes in CIJs are seen in Figure $3 a-b$, and are characterized by a clear interface between the fluids issuing from opposite injectors. The dynamic 
visualization of PLIF images for $R e<110$ shows that the interface between both fluids is quite steady. Also in these images, in the clear fluid side, steady vortices are seen above and below the jets; these vortices result from dyed fluid that is dragged into the left side of the chamber. At steady state each jet feeds a fluid stream forming two segregated streams that flow in parallel toward the outlet, and the initial scale of the jets, $d$, increases to a mixing scale of $D / 2$ that is quite clear from the PLIF images.

Increasing the Reynolds number, in a quite narrow interval of $105<R e<120$ onsets instabilities at the interface between the two parallel streams that start at injectors exit and when reaching the jets impingement point causes a general transition of flow regime in the entire CIJs chamber. This mechanism of the onset of the chaotic flow regimes has been shown in previous PIV (Santos et al. 2008) and PLIF studies (Fonte et al. 2015). When the jets are directly affected from the downstream instabilities, an oscillatory pattern of the jets is triggered. The oscillations of the jets are associated with the shedding of vortices issuing from the jets impingement point. The role of the vortices on mixing is clear from Figure $3 c-f$, where the pancake of fluid that spreads radially from the jets impingement point is seen to engage in a spiral movement upwards and downwards the inlet jets. The fluids that initially have a scale $d$, are striated to mixing laminae an order of magnitude smaller in a distance around $D / 2$ and afterwards the scale of white and dark strias falls below the PIV camera resolution.

The operation at chaotic flow regimes is thus of utmost importance in applications such as RIM where the monomers must be mixed into small enough laminae for reaction to be only limited by diffusion after the mixing chamber (Ranz 1986). This flow regime was thoroughly studied for the case of equal flow rates and similar fluids, yet when the flow rates were not balanced the flow dynamics is completely dissipated. The flow rate ratio is defined as

$$
\phi_{F R}=\frac{\rho_{1} d_{1}^{2} v_{\text {inj_1 }}}{\rho_{2} d_{2}^{2} v_{\text {inj_2 }}}
$$

where indices 1 and 2 indicate the injector side, see Figure $1, d$ is the diameter of the inlet nozzles, $\rho$ is the density and $v_{i n j}$ is the inlet velocity of each jet. Figure 4 shows a set of PLIF images for flow rate ratios from $\phi_{F R}=0.88$ to $\phi_{F R}=1.15$, at $R e=304$, which is above the critical value marking the transition for chaotic flow regimes. The dramatic effect of $\phi_{F R}$ is quite clear from the PLIF images, in a short range of operation where the maximum deviation from $\phi_{F R}=1$ is $15 \%$, the jets are completely pushed into one of the nozzles. In industrial RIM machines this causes polymer to start forming in the inlet nozzles, and for this reason industrial practice establishes a small deviation angle of the jets from the directly opposite direction. Alternative techniques to make ClJs operation more robust are based on the control of the static pressure difference between the opposed jets (Erkoç et al. 2007, Gomes et al. 2016), which enables to control the jets balancing in real time. This technology has not been introduced in commercial RIM machines based on opposed jets mixing chambers and would not overcome the limitation associated to the mixing of fluids with different flow rates.

The prediction of the jets impingement point is thus of utmost importance in ClJs operation. Fonte et al. (2016) introduced a model that describes the impingement point position assuming that the jets act as springs of equal force $F=k l$, where $k$ is the springs' constant and $l$ is the spring length variation. The model gets its name, elastic analogue model, from the spring analogy shown in Figure 5. The variation of the potential energy of each jet is proportional to the jets displacement from the mixing chamber axis, $\Delta E_{P}=k l^{2}$. The ratio of potential energy of the opposed jets is proportional to the ratio of the jets kinetic energy rate, $\frac{E_{K_{-}}}{\dot{E}_{K_{-} 2}}=\frac{l_{1}}{l_{2}}$, and so the jets impingement point displacement is proportional to the kinetic energy feeding rate ratio of the opposed jets 


$$
\phi_{K}=\frac{\rho_{1} d_{1}^{2} v_{i n j \_1}^{3}}{\rho_{2} d_{2}^{2} v_{\text {inj_2 }}^{3}}
$$

Fonte et al. (2016) introduced a correction for the energy dissipation in each jet using the model of a narrow axisymmetric jet (NAJ) due to viscous effects. The axial velocity according to NAJ is

$$
u(x, r)=\frac{3 J}{8 \pi \mu x}\left[1+\frac{1}{4}\left(\frac{C r}{x}\right)^{2}\right]^{-2}
$$

where $C=\sqrt{\frac{3 \rho J}{16 \pi \mu^{2}}}$ is the integration constant, and $J=\pi \rho v_{i n j}^{2} d^{2}$ is the fed's jet momentum ratio. NAJ introduces viscosity related terms, namely the jets Reynolds numbers, in the elastic analogue model for the prediction of the jets impingement point displacement from the mixing axis, $x_{\text {IP }}$. Considering the NAJ model, the jets impingement point position relation $\left(l_{1} / l_{2}\right)$ is given by

$$
\frac{\dot{E}_{K_{-}-1}}{\dot{E}_{K_{-} 2}}=\frac{l_{1}}{l_{2}}=\frac{\int_{0}^{\infty} u_{1}\left(l_{1}, r\right)^{3} 2 \pi \rho_{1} r d r}{\int_{0}^{\infty} u_{2}\left(l_{2}, r\right)^{3} 2 \pi \rho_{2} r d r}=\sqrt{\phi_{K} \frac{R e_{1}}{R e_{2}} \frac{d_{1}}{d_{2}}}
$$

The NAJ model considers a momentum source that is placed at a distance $l^{\prime}=\frac{R e}{20}$ (Fonte et al. 2016) before the inlet, and thus

$$
\frac{D / 2+x_{\mathrm{IP}}+l_{1}^{\prime}}{D / 2+x_{\mathrm{IP}}+l_{2}^{\prime}}=\sqrt{\phi_{K} \frac{R e_{1}}{R e_{2}} \frac{d_{1}}{d_{2}}}
$$

where $x_{\mathrm{IP}}$ is the jets impingement point displacement. Introducing the dimensionless jets impingement point displacement, $\xi=\frac{2 x_{\mathrm{IP}}}{D}$, and solving from Equation 10 considering $l^{\prime}=\frac{R e}{20}$, results in

$$
\xi=\frac{\left[\left(\frac{R e_{2}}{10} \frac{d_{2}}{D}+1\right) \sqrt{\phi_{K} \frac{R e_{1}}{R e_{2}} \frac{d_{1}}{d_{2}}}\right]-\left(\frac{R e_{1}}{10} \frac{d_{1}}{D}+1\right)}{\sqrt{\phi_{K} \frac{R e_{1}}{R e_{2}} \frac{d_{1}}{d_{2}}}+1}
$$

This model enables the design of CIJs for mixing of fluids at non-unitary flow rate ratios, $\phi_{F R} \neq 1$, by changing the diameter of the nozzles so that $\xi=0$. Full derivation of the model, validation, and application to the design of CIJs with $\phi_{F R} \neq 1$ for similar fluids is given in Fonte et al. (2016). Figure 6 shows the results of the validation of the elastic model for the prediction of the jets impingement point from PIV data obtained in the same CIJs geometry described in Figure 1.

The elastic analogue model accounts for differences in the fluid viscosities that indicate the viscosity also plays a role on the jets equilibrium condition. The differences of the liquids viscosities are taken in account in the Reynolds number term $\left(R e_{1}\right.$ and $\left.R e_{2}\right)$ of Equation 11 . The validation of this model was made for different flow rate ratios, but not for mixing of dissimilar fluids. This validation is the main objective of this work and is performed from CFD simulations and PLIF experiments.

\section{Mixing of dissimilar fluids}

Mixing of dissimilar fluids is studied in CIJs, namely from CFD simulations. Figures 7 and 8 show mass fraction maps of two fluids in the axial plane of the ClJs and of the injectors axis. The mass fraction maps were obtained from the 3D CFD simulation of the mixing of fluid 1 with $\mu_{1}=0.04 \mathrm{~Pa} \cdot \mathrm{s}$ injected from the left hand side, with fluid 2 with $\mu=0.02 \mathrm{~Pa} \cdot \mathrm{s}$ on the right hand side. The left hand side Reynolds number are fixed at $R e_{1}=50$ in Figure 7, and at $R e_{1}=100$ in Figure 8, below the critical Reynolds number. The right hand side jet flow rate is varied from a flow rate ratio of $\phi_{F R}=0.46$ and $\phi_{K}=0.1$, Figure 7a and Figure 8a, to $\phi_{F R}=2.15$ and $\phi_{K}=10$, Figure $7 \mathrm{i}$ and Figure $8 \mathrm{i}$. 
In Figure 7a for $R e_{1}=50$ and $\phi_{K}=0.1$, where for the opposite jet $R e_{2}=215$, it can be seen the white jet flowing from the right hand side almost into the opposite injector. Fluid issuing from the left injector is directed towards the close top of the mixing chamber where a large vortex filled of white fluid makes the blue fluid flow close to the chamber walls. In a 3D movement not shown in the imaged plane the blue fluid circles to the bottom part of the white jet, issuing from the right hand side injector. Nevertheless, the mixing dynamics is quite weak with the lower flow rate component flowing close to the chamber walls, regions of weaker flow dynamics.

Figure 9 shows pathlines for the case $R e_{1}=50$ and $\phi_{K}=0.1$ where the pathlines issuing from left injector are represented in black and the opposite injector pathlines in grey. The ClJs in Figure 9a are displayed in a view where the injector corresponding to the left hand side in Figure 7, is now the one in the front left position of the mixer. In Figure $9 b$ and $9 c$ the relative position of the injectors is kept, Figure $9 \mathrm{~b}$ is a front view, the same as Figure $7 \mathrm{a}$, and Figure $9 \mathrm{c}$ is a view from the ClJs closed top. The pathlines show the 3D patterns of the flow that transport the fluid from the CIJs headspaces, above the jets, to immediately downstream the jets. The right hand side jet is clearly dominant and impinges on the opposite side of the CIJ mixer. After impinging on the opposite side of the $\mathrm{CIJ}$ mixer, fluid from the dominant jet spreads radially, and around this jet a large vortex occupying all the headspace of the $\mathrm{CIJ}$ is formed. This vortex makes the blue fluid to circulate close to the $\mathrm{CIJ}$ walls, and also drags some portions of blue fluid making it to flow around the white jet and transports this blue fluid downwards the jets.

Decreasing the right hand side jet flow rate, Figures 7b and 7c, to $\phi_{F R}=0.585$ and $\phi_{F R}=0.794$ $\left(\phi_{K}=0.2\right.$ and $\left.\phi_{K}=0.5\right)$, shows the impingement point of the jets moving slightly towards the mixing chamber axis. The blue jet is not completely pushed towards the mixing chamber top, but even so, it is squeezed into the mixing chamber walls. Although the blue jet is now penetrating further into the mixing chamber, it is still flowing next to the wall. These flow patterns, where the jets impinge quite close to one inlet nozzle, are quite prone to clogging in RIM processes, due to the formation of polymer directly at the nozzles of the CIJs. Figures $10 \mathrm{~b}$ and $10 \mathrm{c}$ show the pathlines for these simulations, from where it is seen the jets impinging slightly further from the left nozzle than for $\phi_{K}=0.1$ (Figure 10a). The deflection of the left hand side jet is maintained in the range $\phi_{K}=$ 0.1 to 0.5 .

Only when $\phi_{K}$ is close to one, $0.67<\phi_{K}<2$, the jets impinge at central positions of the ClJs mixer, without one of the jets overtaking the other. This corresponds to a limited range of flow rate ratios $0.88<\phi_{F R}<1.3$, which highlights the process extreme dependence on the flow rate ratio control (Erkoç et al. 2007). When the jets impinge closer to the mixing chamber axis, two upper vortices are formed above the jets, and downstream the jets, two streams appear, one white and one blue that flow side by side towards the outlet. The overall flow regime closely resembles the steady state flow regime observed for mixing of equal flow rates and fluids when the jets Reynolds number is bellow 120. When the fluids have different viscosities, $\mu_{1}=2 \mu_{2}$, the impingement point at $\phi_{K}=1$ is no longer coincident with the mixing chamber axis, although it is close to it. This shows that kinetic energy flux is the dominant parameter regarding the equilibrium of the opposed jets (Fonte et al. 2016), although viscosity also plays a role. The pathlines in Figure 10 also show the impinging of the jets close to the mixing chamber axis in the range $0.67<\phi_{K}<2$. Although there is an equilibrium of the jets, the flow in the chamber is not completely symmetric and so the tracer maps differ from the PLIF images in Figures 3a and $b$.

Further decreasing the right jet flow rate to $\phi_{K}=2$ and $\phi_{K}=10$ creates flow patterns to those for $\phi_{K}=0.1$ and $\phi_{K}=0.2$, but now with the blue jet overtaking the white one. The dominant blue jet for $\phi_{K}=10$ is at $R e=50$, while in $\phi_{K}=0.1$ the dominant jet Reynolds number was at $R e=215$. This causes no meaningful difference in the flow patterns, because the dominant phenomenon in 
these cases is the stabilization of the flow by the effect of the wall of the CIJs where the dominant jet impacts and dissipates its energy.

For $R e_{1}=100$ Figure 8 shows similar effect of $\phi_{K}$ on the jets impingement point position. The main difference from $R e_{1}=50$ to $R e_{1}=100$ cases is the increase on flow instability, this is of particular importance for smaller $\phi_{K}$ values, $\phi_{K}=0.1$, where the dominant blue jet Reynolds number is $R e_{2}=430$. The large vortex in the ClJs headspace occurring for $\phi_{K}=0.1$ and $R e_{1}=50$ that was setting the distribution of blue fluid to downstream positions is no longer identified, instead some unstable flow patterns are promoting interactions between blue and white although the blue fluid is mainly kept close to the walls. The instability for $R e_{1}=100$ and $\phi_{K}=0.1$ is promoted by the impingement of the jet with more kinetic energy into the wall. Nevertheless the jets are not being directly engulfed by vortices being formed in the CIJs around the jets, in a generalised chaotic flow that is able of promoting fast mixing of two fluids. This increase in flow instability is also clear from pathlines in Figure 11 that are becoming increasingly random.

Decreasing the flow rate of the right hand side jet, the jets impingement point moves towards the mixing chamber axis, particularly in the range of $0.77 \leq \phi_{K} \leq 2$. The decrease of the Reynolds number of the jet makes these flow patterns more stable and similar to the ones already described for Figure 7 and 10. Similarly to the cases where $R e_{1}=50$, for $R e_{1}=100$ the jets are not impinging at the mixing chamber axis when $\phi_{K}=1$. Larger Reynolds numbers where the flow becomes dynamic were not simulated.

Figure 12 shows the plots of the normalised displacement of the jets impingement point from the mixing chamber axis, $\xi$, as a function of the jets kinetic energy rate ratio, $\phi_{K}$, for the cases where $R e_{1}=50$ and $R e_{1}=100$. These plots clearly show that the jets position is extremely sensitive to the $\phi_{K}$ values. Furthermore these plots also show that the balancing condition is no longer $\phi_{K}=1$, which is changed by the fact that $R e_{1} \neq R e_{2}$, causing a slight offset in the equilibrium condition. This offset is predicted from the elastic analogue equation, see Equation 11, also plotted in Figure 12. The model predicts the behaviour of the system and position of the impingement point, particularly in the validity range $-1<\xi<1$. For $\operatorname{Re}_{1}=100$ the CFD results are coincident with the elastic model prediction. For $R e_{1}=50$ the model fitting is not as good as was observed for $R e_{1}=$ 100 and from previous work with similar fluids (Fonte et al. 2016), nevertheless the results are in a range that enables to use this model for design without risking one jet being completely overtaken by the opposite one.

Experiments were made to validate these results. Regarding experiments, there is a $3 \%$ difference of the liquids density, $\rho_{1}=1208 \mathrm{~kg} / \mathrm{m}^{3}$ and $\rho_{2}=1176 \mathrm{~kg} / \mathrm{m}^{3}$, which has no major effect on the jets balancing. Another point to be made is that the flow rate control is set within $5 \%$, which for a system so sensitive to $\phi_{K}$ can have impact on the impingement point positioning. Figure 13 and Figure 14 show the PLIF images, obtained at the plane defined by the mixing chamber and injectors axis, for the mixing of two dissimilar fluids: $\mu_{1}=0.04 \mathrm{~Pa} \cdot \mathrm{s}$ and $\mu_{2}=0.02 \mathrm{~Pa} \cdot \mathrm{s}$. A white frame is drawn around the CIJs mixing chamber. The left jet, having larger viscosity $\mu_{1}=0.04 \mathrm{~Pa} \cdot \mathrm{s}$, is dyed with rhodamine, and so the fluid issuing from this jet appears in white colour in the PLIF images.

The PLIF images in Figure 13 are obtained for a fixed $R e_{1}=50$ and a varying opposed jet so $\phi_{K}$ goes from 0.1 to 10 . When $\phi_{K}=0.1$ the deviation of the left white jet towards the mixing chamber top is clear. This jet then circles around the opposed jet making this white liquid to appear bellow the dark jet. In the CIJs headspace only one large vortex is observed. These overall flow patterns are consistent with description of CFD simulations from mass concentration maps, Figure 7a, and from the pathlines in Figure 9 and Figure 10a. When the flow rate of the right jet is decreased corresponding to $\phi_{K}=0.2$, the jets impingement point is slightly shifted to the right, although the fluid from the left injector is still pushed into the left side of the chamber. The white jet is not deviated around the ClJs top walls as in $\phi_{K}=0.1$, and so white fluid is now more confined into a 
single side of the mixer. Even though there is enough white fluid being transported to the opposite side to create thin laminas that highlight the vortices in the CIJs right side. This flow pattern corresponds more to the one observed in CFD for $\phi_{K}=0.5$. The $5 \%$ deviation on flow rates amounts up to $30 \%$ deviation on $\phi_{K}$, and so it is possible that the experimental results are more deviated towards the larger $\phi_{K}$ values.

In a narrow range of kinetic rate ratios that correspond to $0.5<\phi_{K}<2$ the jets impingement point is close to the mixing chamber axis. This was also observed from the CFD simulations, and the same observations are directly applied to the PLIF data. The flow patterns are similar to the ones observed for the steady state flow regime obtained for $\mathrm{ClJs}$ with jets having equal flow rates and viscosities. This provides further experimental evidence of the key role that kinetic energy rate ratio has on the balancing of opposed jets.

Further increasing $\phi_{K}$ makes the white jet to overcome the dark one. The flow is the symmetric of the previously described for the lower $\phi_{K}$ values, the main difference is that for this case PLIF results show more clearly the flow of the liquid from the dominant jet, while for $\phi_{K}<0.5$ the weaker jet flow was clearer. For $\phi_{K}>2$ the PLIF image shows the white dominant jet almost impinging in the opposite wall, pushing the opposite jet into the right side of the mixing chamber and making it to flow close to the CIJs walls. The upper vortices being fed of white fluid with some of the dark fluid being engulfed, is clear for the $\phi_{K}>2$ cases.

Figure 14 shows the PLIF images obtained for a fixed $R e_{1}=100$ and viscosity ratio $\mu_{1} / \mu_{2}=2$. The same overall flow behaviour described for the $R e_{1}=50$ is also observed for the $R e_{1}=100$. The main difference is an increasing instability of the flow patterns when $\phi_{K}=0.1$ and $\phi_{K}=0.2$. This was also observable from CFD data in Figure 8 and Figure 11. For the cases $\phi_{K}=0.1$ and $\phi_{K}=0.2$ the right hand side jet Reynolds numbers are 423 and 336, respectively, at these ranges the jets upon impinging the opposed wall have some dynamic behaviours. For balanced flows, such as the one in Figure 13d, where the Reynolds numbers are $R e_{1}=100$ and $R e_{2}=197$, the flow regime is steady and similar to the steady flow regimes obtained for equal fluids and flow rates, although the right hand side jet is clearly above the critical Reynolds number that onsets chaotic flow regimes in CIJs with symmetric conditions of flow rate and fluids.

The PLIF experiments were run for Reynolds numbers above 100, namely for $R e_{1}=125$ and $R e_{1}=$ 150 , Figure 15 and Figure 16, respectively. For these cases the $\phi_{K}$ values were set in the range $0.2 \leq \phi_{K} \leq 5$. The flow patterns are similar to those described for the $R e_{1}=100$ PLIF images of Figure 14. The main difference is for the case $\phi_{K}=1$ at $R e_{1}=150$, Figure $16 \mathrm{c}$, where the opposite jets strengths are balanced, as can be seen by the jets impinging close to the mixing chamber axis. The flow is no longer the steady state segregated flow where the fluids from right and left injector flow segregated in the mixing chamber creating two parallel streams, a white and a dark stream, as can be seen in Figure $13 \mathrm{~d}, 14 \mathrm{~d}$, and $15 \mathrm{c}$. For $\phi_{K}=1$ at $R e_{1}=150$ the opposite jets impinge at the mixing chamber axis and spread radially forming a sort of a flow pancake as seen from previous works with symmetric flow conditions (Wood et al. 1991, Unger et al. 1998, Nakamura and Brodkey 2000). Around the jets, vortices are formed that engulf this pancake like structure. These vortices are clear in Figure $16 \mathrm{c}$ around the right hand side jet, where a streak of white and dark fluid is seen issuing from the jets impingement point upwards and then being bent into the inside of a spiral pattern. A similar pattern is observed downwards, although not so clearly. In this work only the top part of the mixing chamber is imaged, and so the structure of the mixture in the downward section of the mixing chamber is not seen. The pattern of the mixture formed by the two fluids in the upper part of the ClJs, from the closed top down to a distance $D$ from the top, is the same imaged for symmetric ClJs operation (Fonte et al. 2011), where after this mixing region is formed a thin lamellar structure of both fluids interlaid. The result in Figure $15 \mathrm{c}$ shows the ability in $\mathrm{ClJs}$ to create the same mixing structure for two dissimilar fluids when the opposite jets are balanced to impinge in the 
mixing chamber axis. For dissimilar fluids, the critical Reynolds number marking the onset of chaotic flow regimes is given from the jet with the lower Reynolds number, and is in the range of values known for CIJs operating at symmetric conditions.

Previous experimental evidence had shown that the onset of mixing in CIJs was determined from the Reynolds number of the more viscous fluid (Malguarnera and Suh 1977, Nguyen and Suh 1983). This evidence was generated from RIM experiments with actual reactive polymerization system.

Nevertheless, the jets balancing was not guaranteed and the onset of mixing was observed indirectly from parameters as the adiabatic temperature rise. To our knowledge, this is the first work on the onset of chaotic flow regimes in CIJs when the fluids have a viscosity ratio, and the opposed jets are balanced.

Figure 17 shows the fitting of the elastic analogue model to the experimental data from PLIF results. The bars in Figure 17 represent the standard deviation of $\xi$ measured from 10 PLIF images for each Reynolds number and $\phi_{K}$. The value of $\xi$ is obtained from the plot of the image colour value plotted along a line defined from the injectors' axis, the contacting of the two jets is marked by a steep gradient in this plot. The results are also affected by the flow rate ratio deviation, which amounts to a deviation of $30 \%$ of $\phi_{K}$; this deviation is not represented in Figure 16. These results provide experimental validation of the elastic analogue model namely for $R e_{1}>50$ where the model predictions coincide with experimental results. For $R e_{1}=50$ the experimental results have the same deviation observed from CFD data. Therefore, the PLIF experiments corroborate the CFD results and provide validation of the capability of the elastic model to predict the contact point of the jets in ClJs mixers for fluids with different viscosities.

\title{
Conclusions
}

CIJs are able to mix dissimilar fluids of different viscosities, under a chaotic flow regime that is characterised by the generation of vortices that engulf both fluids, forming a structure of thin lamella. The necessary condition for mixing is the balancing of the jets, making them to impinge at the CIJs chamber axis. The elastic analogue model predicts the tendency and actual position of the jets impingement point, with particular accuracy for Reynolds numbers of industrial relevance, above 150. This work enabled to determine the dynamics of mixing of dissimilar fluids and the onset of chaotic flow regime from the visualization of PLIF data and CFD results. The transition Reynolds number to chaotic flow regime occurs when the jet with the lower Reynolds numbers is in the range $120<R e<150$. The PLIF results and CFD simulations of a CIJ mixer enabled the validation of the elastic analogue model as a design tool for CIJ mixers for fluids with dissimilar viscosities.

\section{Acknowledgements}

This work was financed by projects UID/EQU/50020/2013 and PTDC/QEQ-FTT/0041/2014-POCI-010145-FEDER-016851 - funded by FEDER funds - Programa Operacional Competitividade e Internacionalização (POCI) and by national funds through FCT - Fundação para a Ciência e a Tecnologia, I.P. and by QREN, ON2 and FE under the Programme COMPETE2020 (Projects NORTE-07-0162-FEDER000050 and NORTE-07-0124-FEDER-000013); and by the FCT scholarship PD/BD/135060/2017.

\author{
Notation \\ $d$ - diameter of the injectors of the CIJs \\ $C_{A}-$ Concentration of species $\mathrm{A}$ \\ $D$ - Diameter of the CIJs
}


$\mathcal{D}_{A B}$ - Diffusivity of species $\mathrm{A}$

$E_{K}$ - Rate of kinetic energy

$F$ - modulus of force

$h$ - distance from injectors axis to ClJs closed top

$H$ - Height of the ClJs

$l$-Momentum source distance position for the NAJ model

$k$ - Spring constant for Hooke's Law

$p$ - pressure

$r$ - radial position of the jet

$R e-$ Reynolds number of the jets

$\mathbf{u}$ - velocity vector

$t$ - time

$x_{I P}$ - jets impingement point displacement from ClJs axis

\section{Greek letters}

$\phi_{F R}$ - flow rate ratio of the jets

$\phi_{K}-$ kinetic energy rate ratio of the jets

$\mu$ - dynamic viscosity of the fluids

$\xi$ - - jets impingement point normalized displacement from CIJs axis

$\rho$ - density of the fluids

$v_{i n j}$ - superficial flow velocity at the CIJs injectors

indices

1 - fluid 1 , injected from the right hand side of the CIJs

2 - fluid 2, injected from the left hand side of the CIJs

\section{References}

Erkoç, E., R. J. Santos, M. I. Nunes, M. M. Dias and J. C. B. Lopes (2007). "Mixing dynamics control in RIM machines." Chemical Engineering Science 62(18): 5276-5281.

Fonte, C. P., R. J. Santos, M. M. Dias and J. C. B. Lopes (2011). "Quantification of mixing in RIM using a non-diffusive two-phase flow numerical model." International Journal of Chemical Reactor Engineering 9: A114. 
Fonte, C. P., M. A. Sultan, R. J. Santos, M. M. Dias and J. C. B. Lopes (2015). "Flow imbalance and Reynolds number impact on mixing in Confined Impinging Jets." Chemical Engineering Journal 260: 316-330.

Fonte, C. P., M. A. Sultan, R. J. Santos, M. M. Dias and J. C. B. Lopes (2016). "An elastic analog model for controlling the impingement point position in confined impinging jets." AlChE Journal 62(6): 2200-2212.

Gomes, N. M. O., C. P. Fonte, C. C. e. Sousa, A. J. Mateus, P. J. Bártolo, M. M. Dias, J. C. B. Lopes and R. J. Santos (2016). "Real time control of mixing in Reaction Injection Moulding." Chemical Engineering Research and Design 105: 31-43.

Johnson, D. A. (2000a). "Experimental and Numerical Examination of Confined Laminar Opposed Jets. Part I Momentum Imbalance." International Communications in Heat and Mass Transfer 27(4): 443-454.

Johnson, D. A. (2000b). "Experimental and Numerical Examination of Confined Laminar Opposed Jets. Part II Momentum Balancing." International Communications in Heat and Mass Transfer 27(4): 455-463.

Johnson, D. A. and P. Wood (2000). "Self-Sustained Oscillations in Opposed Impinging Jets in an Enclosure." Canadian Journal of Chemical Engineering 78(5): 867-875.

Johnson, D. A., P. Wood and A. N. Hrymak (1996). "The Effect of Geometrical Parameters on the Flow Field of an Opposed Jet RIM Mix Head: Equal Flow and Matched Fluids." Canadian Journal of Chemical Engineering 74(1): 40-48.

Lee, L. J., J. M. Ottino, W. E. Ranz and C. W. Macosko (1980). "Impingement Mixing in Reaction Injection Molding." Polymer Engineering and Science 20(13): 868-874.

Malguarnera, S. C. and N. P. Suh (1977). "Liquid Injection Molding I. An Investigation of Impingement Mixing." Polymer Engineering and Science 17(2): 111-115.

Nakamura, S. and R. S. Brodkey (2000). Direct and Large Eddy Simulation of the Three-Dimensional Unsteady Flows in the Counter-Jet Mixing Vessel. ASME Fluids Engineering Summer Conference, Boston, Massachusetts.

Nguyen, L. and N. Suh (1983). Effect of High Reynolds Number on the Degree of Mixing in RIM Processing.

Ranz, W. E. (1986). "Analysis of Reaction Processes in Which Microscopic Heterogeneities Appear: Scale-Up and Scale-Down of Polymerization Reactions." Industrial \& Engineering Chemistry Fundamentals 25(4): 561-565.

Santos, R. J., E. Erkoç, M. M. Dias, A. M. Teixeira and J. C. B. Lopes (2008). "Hydrodynamics of the mixing chamber in RIM: PIV flow-field characterization." AlChE Journal 54(5): 1153-1163.

Santos, R. J. and M. A. Sultan (2013). "State of the Art of Mini/Micro Jet Reactors." Chemical Engineering \& Technology 36(6): 937-949.

Santos, R. J., A. M. Teixeira, E. Erkoç, M. A. Sultan, A. Karpinska, M. M. Dias and J. C. B. Lopes (2010). "Validation of a 2D CFD Model for Hydrodynamics' Studies in CIJ Mixers." International Journal of Chemical Reactor Engineering 8: A32.

Tucker, C. L. and N. P. Suh (1980). "Mixing for reaction injection molding II. Impingement mixing of fiber suspensions." Polymer Engineering \& Science 20(13): 887-898.

Unger, D. R., F. J. Muzzio and R. S. Brodkey (1998). "Experimental and Numerical Characterization of Viscous Flow and Mixing in an Impinging Jet Contactor." The Canadian Journal of Chemical

Engineering 76: 546-555.

Wood, P., A. N. Hrymak, R. Yeo, D. A. Johnson and A. Tyagi (1991). "Experimental and Computational Studies of the Fluid Mechanics in an Opposed Jet Mixing Head." Physics of Fluids A 3(5): 1362-1368. 


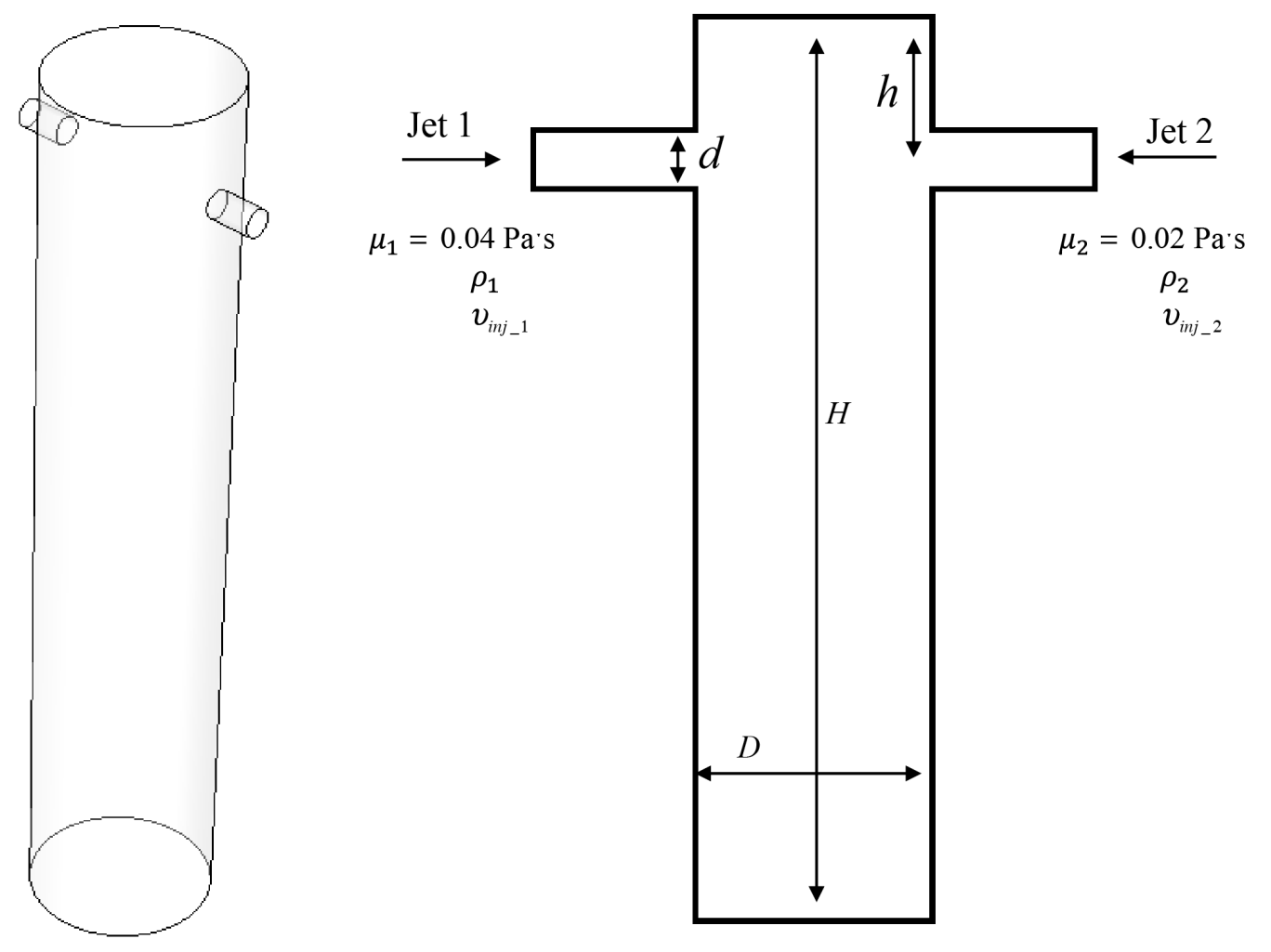

Figure 1 - Geometry of experimental and CFD model of the CIJs, and boundary conditions for the CIJs 3D CFD model. 

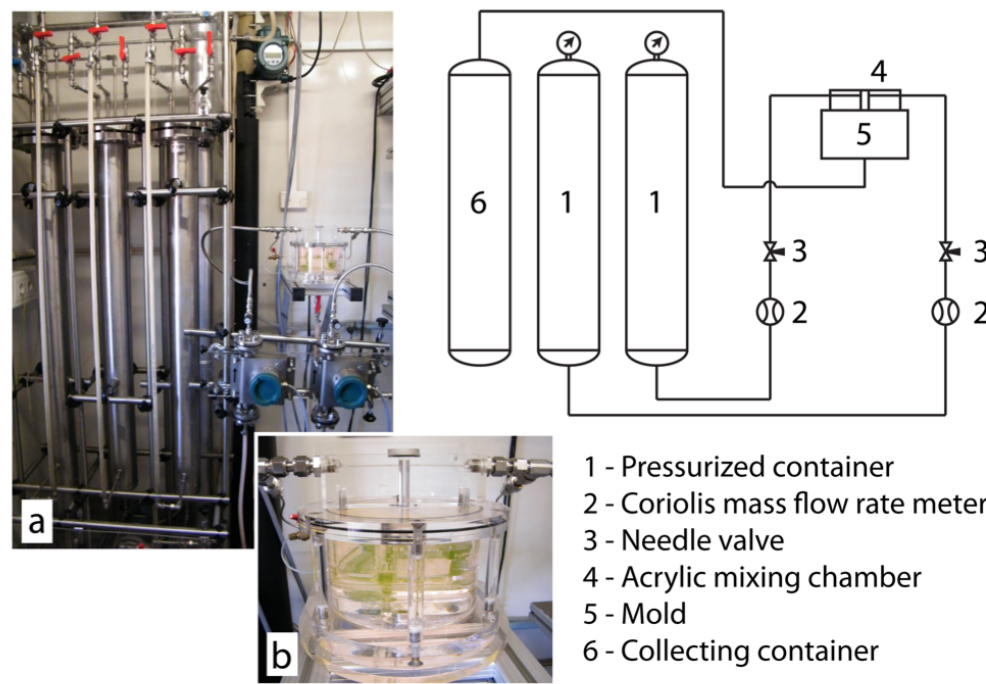

1 - Pressurized container

2 - Coriolis mass flow rate meter 3 - Needle valve

4 - Acrylic mixing chamber

5 - Mold

6 - Collecting container

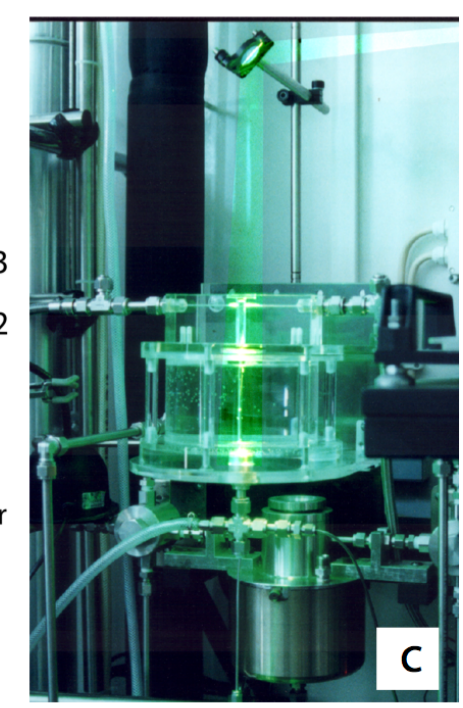

Figure 2 Experimental setup for the PLIF experiments, a) fluid dispensing setup, b) transparent CIJs mixer made of acrylic, c) CIJs during PLIF experiments. 


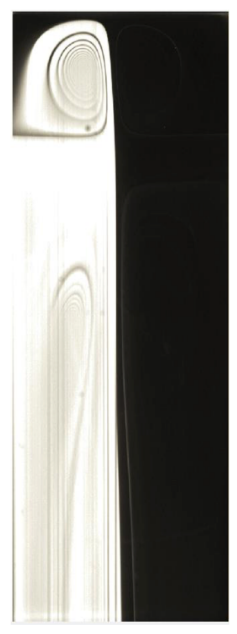

a)

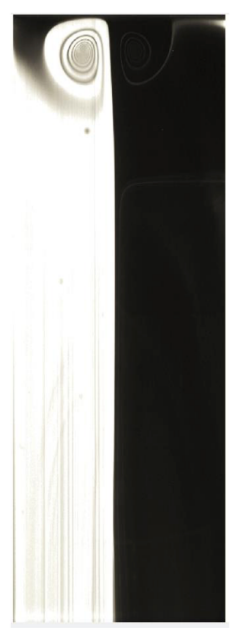

b)

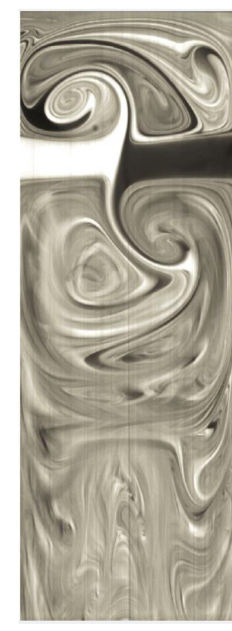

c)

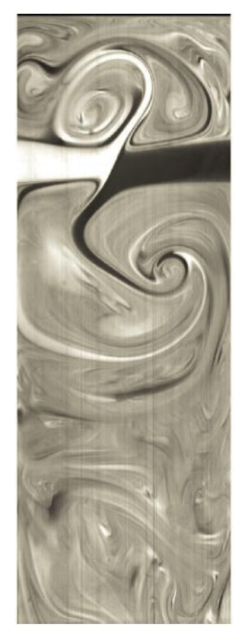

d)

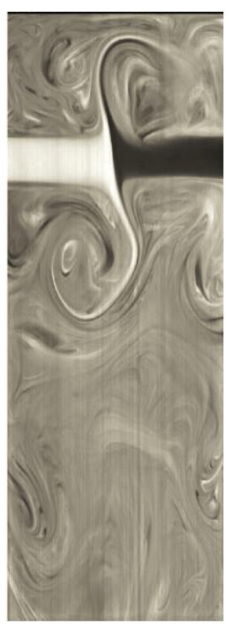

e)

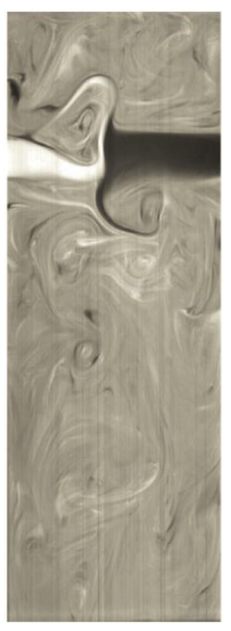

f)

Figure 3 - PLIF image of ClJs operating at symmetric conditions, equal flow rate and fluid from both injectors, at Reynolds numbers: a) $R e=51$, b) $R e=103$, c) $R e=111$, d) $R e=$ 120 , e) $R e=201$ and f) $R e=304$. 


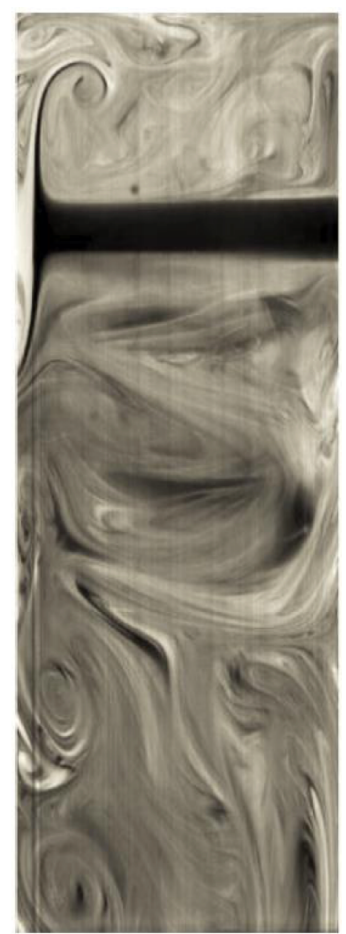

a)

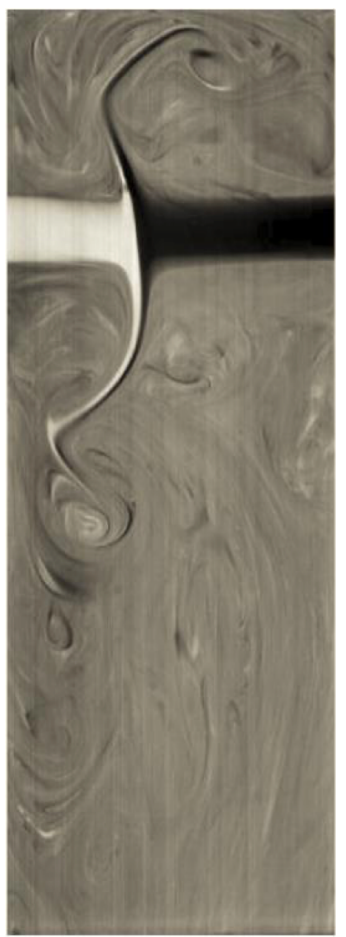

b)

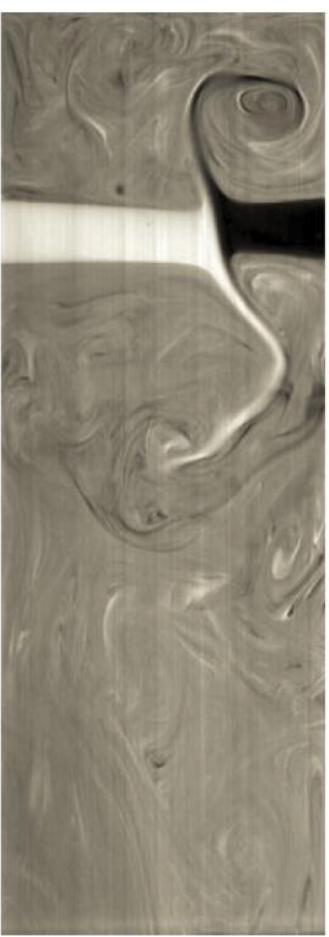

c)

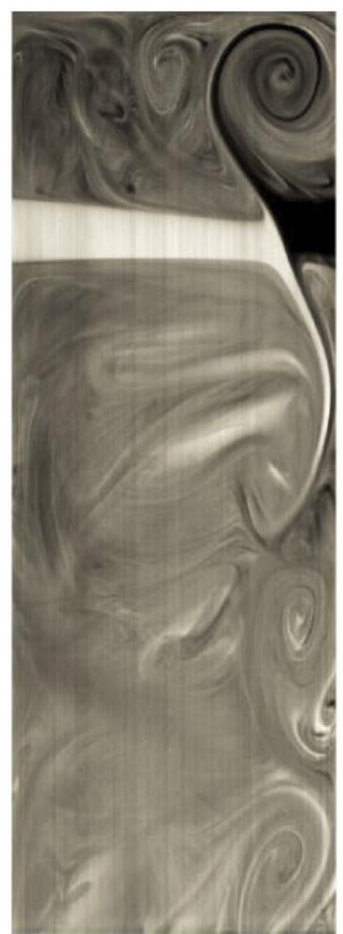

d)

Figure 4 - PLIF images of CIJs mixing chamber for the mixing of similar fluids, with one jet at $R e=304$ and flow rate ratios: a) $\phi_{F R}=0.88$, b) $\phi_{F R}=0.97$, c) $\phi_{F R}=1.04$ and d) $\phi_{F R}=$ 1.15 . 


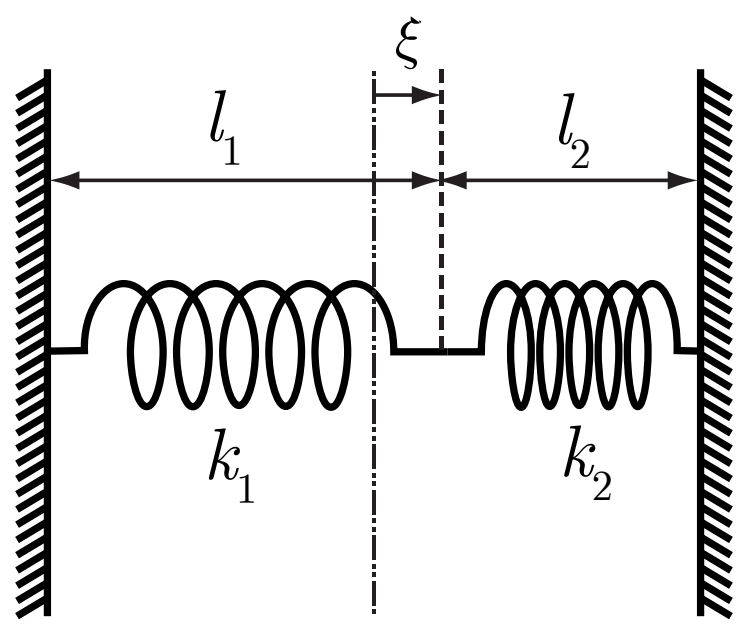

Figure 5 - Model drawing of an elastic analogue representing the opposed jets interaction. 


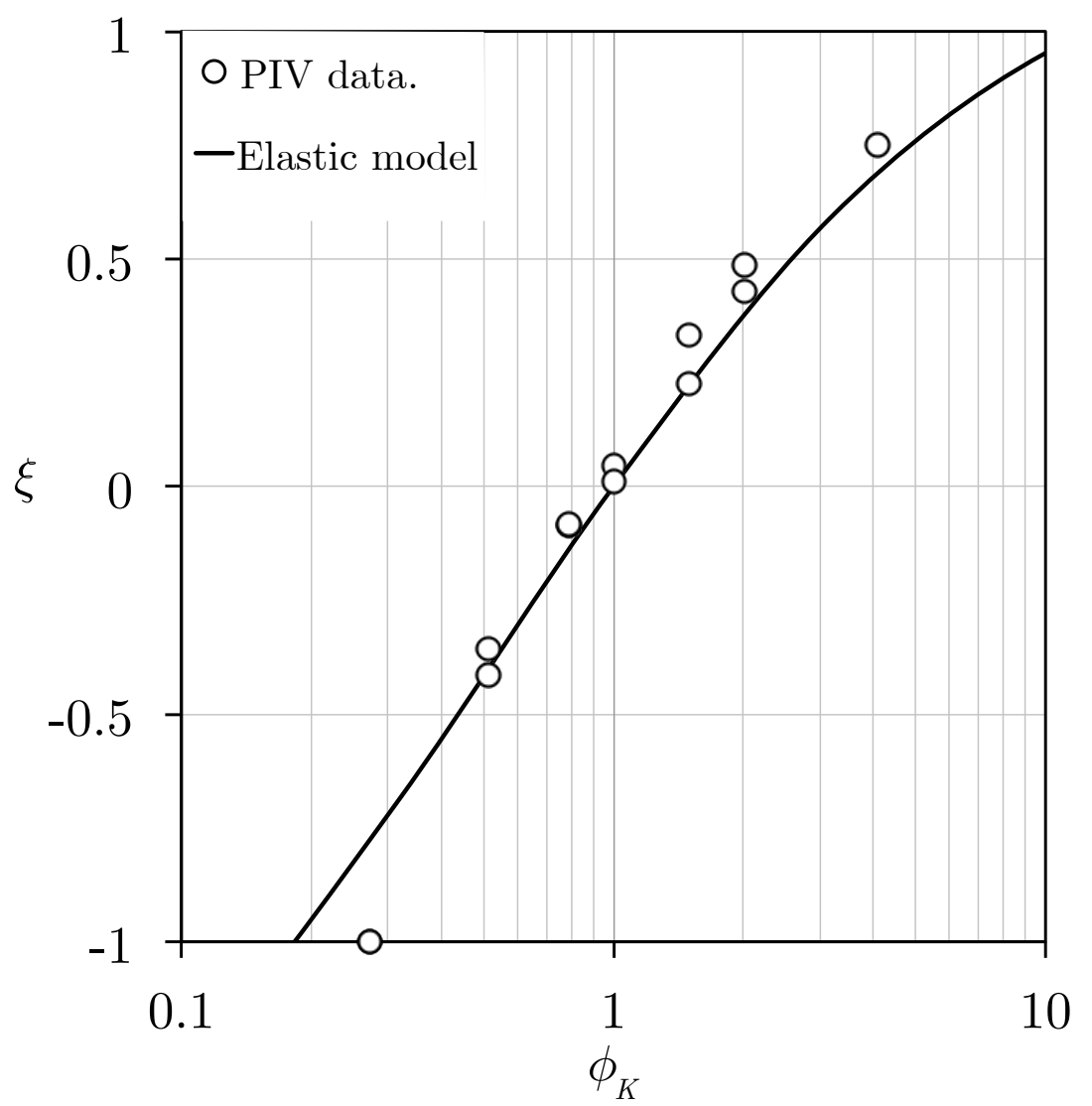

Figure 6 - Particle Image Velocimetry experimental data for the jets displacement from the CIJs mixing chamber axis at $R e=100$ for similar fluids mixing at several $\phi_{K}$ values. 


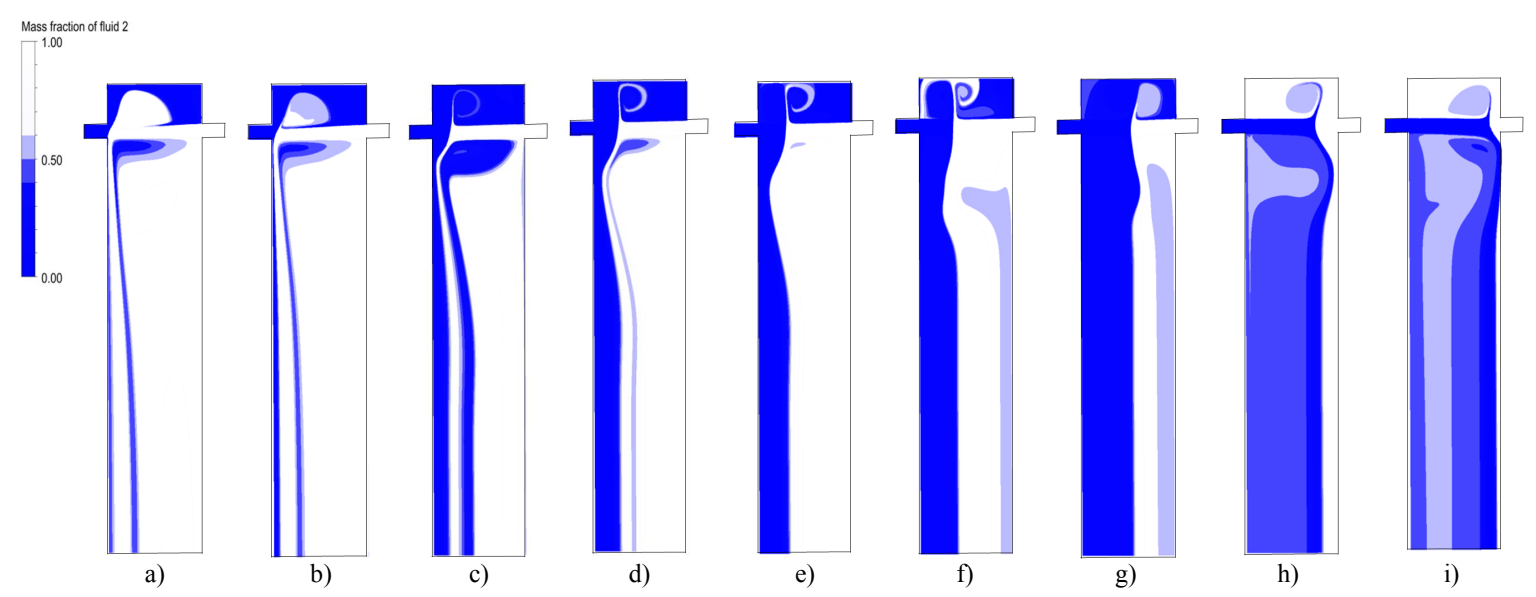

Figure 7 - Mass fraction maps of fluid 2, $\mu_{2}=0.02 \mathrm{~Pa} \cdot \mathrm{s}$, being mixed with fluid $1, \mu_{1}=$ $0.04 \mathrm{~Pa} \cdot \mathrm{s}$, from 3D CFD simulations for $R e_{1}=50$ and a) $\left.\phi_{K}=0.1, \mathrm{~b}\right) \phi_{K}=0.2$, c) $\phi_{K}=$ 0.5 , d) $\phi_{K}=0.67$, e) $\phi_{K}=0.77$, f) $\phi_{K}=1$, g) $\phi_{K}=2$, h) $\phi_{K}=5$ and f) $\phi_{K}=10$. 


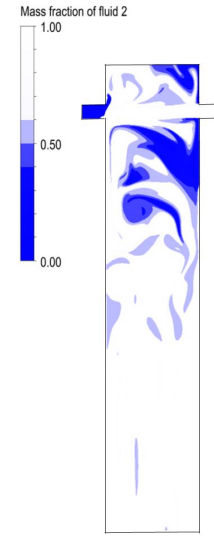

a)

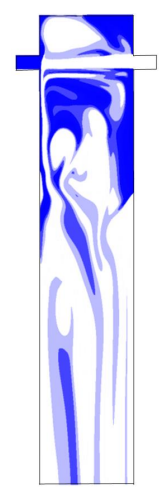

b)

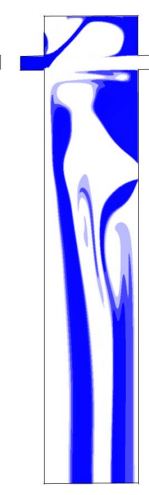

c)

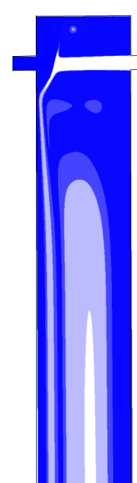

d)

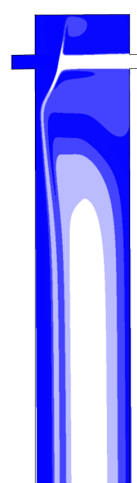

e)

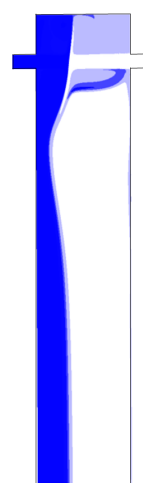

f)

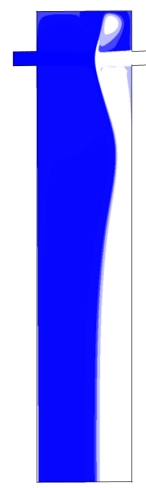

g)

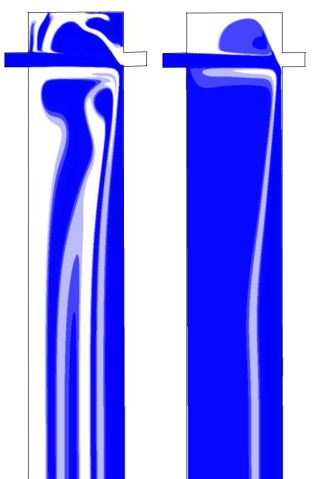

h)

i)

Figure 8 - Mass fraction maps of fluid $2, \mu_{2}=0.02 \mathrm{~Pa} \cdot \mathrm{s}$, being mixed with fluid $1, \mu_{1}=$ $0.04 \mathrm{~Pa} \cdot \mathrm{s}$, from 3D CFD simulations for $R e_{1}=100$ and a) $\left.\phi_{K}=0.1, \mathrm{~b}\right) \phi_{K}=0.2$, c) $\phi_{K}=$ 0.5 , d) $\phi_{K}=0.67$, e) $\phi_{K}=0.77$, f) $\phi_{K}=1$, g) $\phi_{K}=2$, h) $\phi_{K}=5$ and f) $\phi_{K}=10$. 


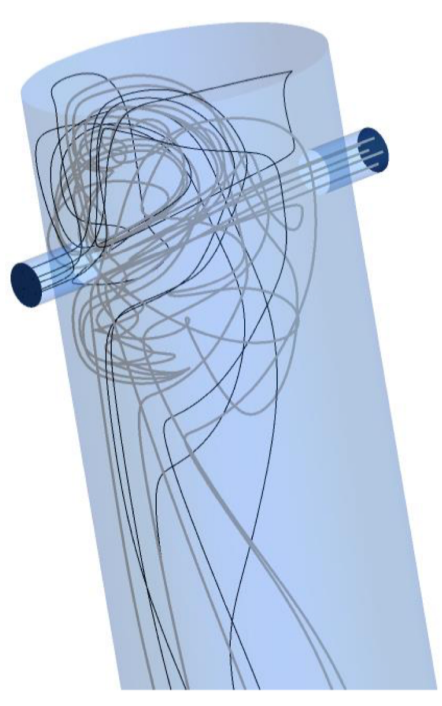

a)

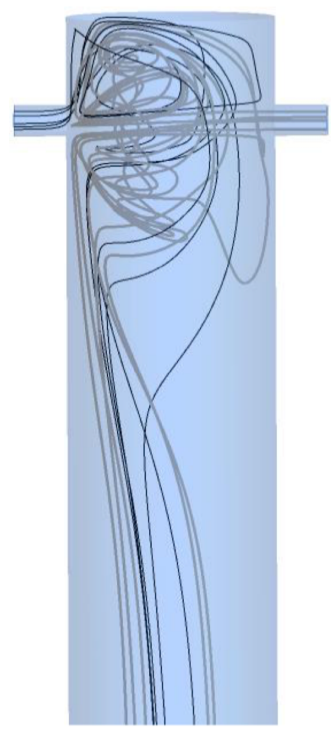

b)

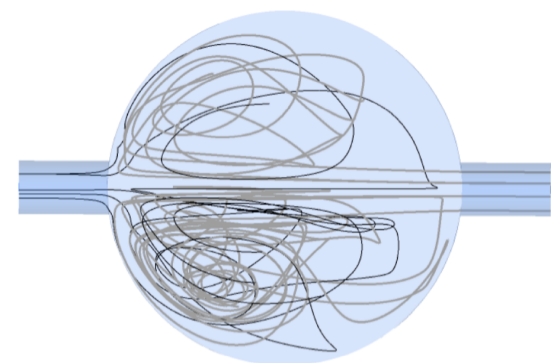

c)

Figure 9 - Path lines from 3D CFD simulation for $R e_{1}=50$ and $\phi_{K}=0.1$ and $\mu_{1}=0.04 \mathrm{~Pa}$. $\mathrm{s}$ and $\mu_{2}=0.02 \mathrm{~Pa} \cdot \mathrm{s}$. 


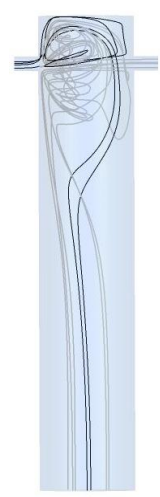

a)

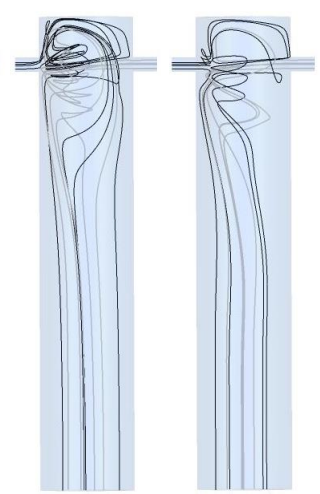

b)

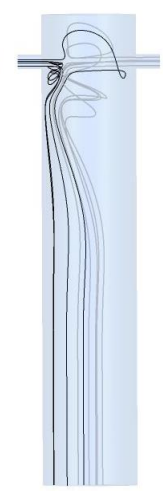

d)

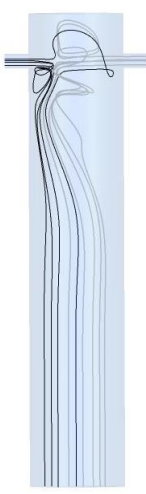

e)

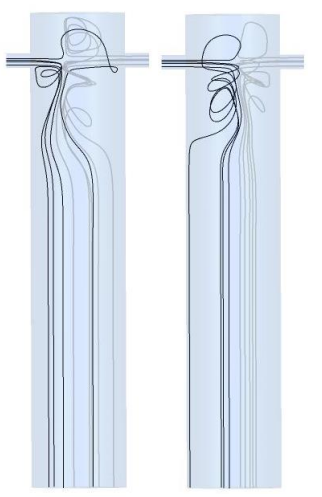

g)

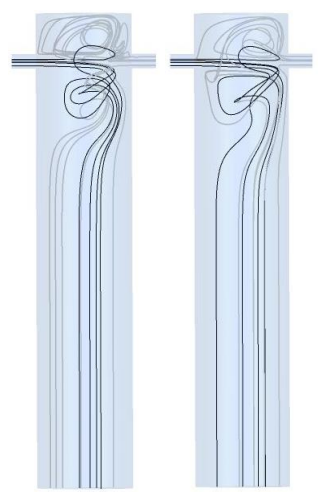

h)

Figure 10 - Path lines from 3D CFD simulations for $R e_{1}=50$ and a) $\phi_{K}=0.1$, b) $\phi_{K}=0.2$, c) $\phi_{K}=0.5$, d) $\phi_{K}=0.67$, e) $\phi_{K}=0.77$, f) $\phi_{K}=1$, g) $\phi_{K}=2$, h) $\phi_{K}=5$ and f) $\phi_{K}=10$ and $\mu_{1}=0.04 \mathrm{~Pa} \cdot \mathrm{s}$ and $\mu_{2}=0.02 \mathrm{~Pa} \cdot \mathrm{s}$. 


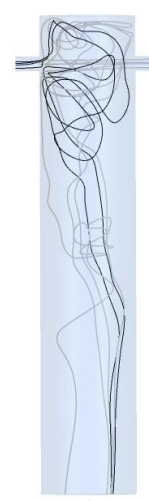

a)

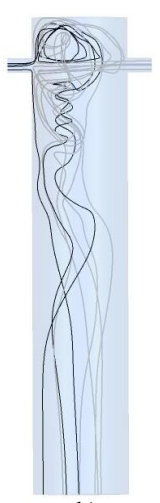

b)

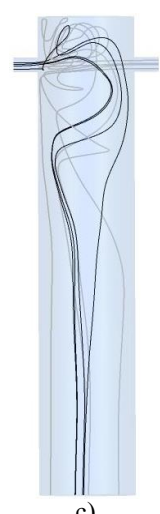

c)

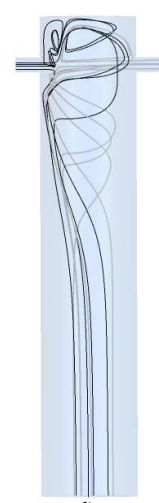

d)

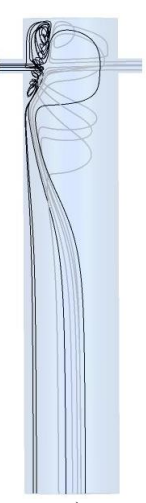

e)

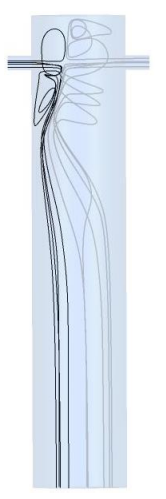

f)

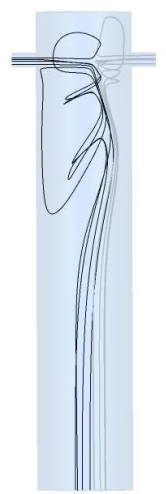

g)

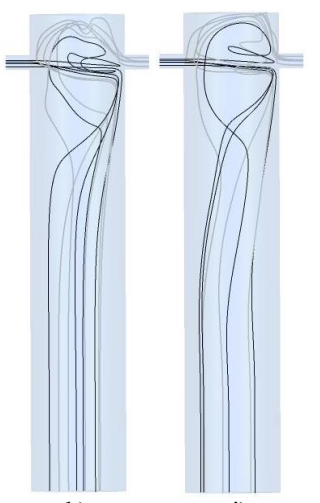

Figure 11 - Path lines from 3D CFD simulations for $R e_{1}=100$ and a) $\phi_{K}=0.1$, b) $\phi_{K}=$ 0.2 , c) $\phi_{K}=0.5$, d) $\phi_{K}=0.67$, e) $\phi_{K}=0.77$, f) $\phi_{K}=1$, g) $\phi_{K}=2$, h) $\phi_{K}=5$ and f) $\phi_{K}=$ 10 and $\mu_{1}=0.04 \mathrm{~Pa} \cdot \mathrm{s}$ and $\mu_{2}=0.02 \mathrm{~Pa} \cdot \mathrm{s}$. 

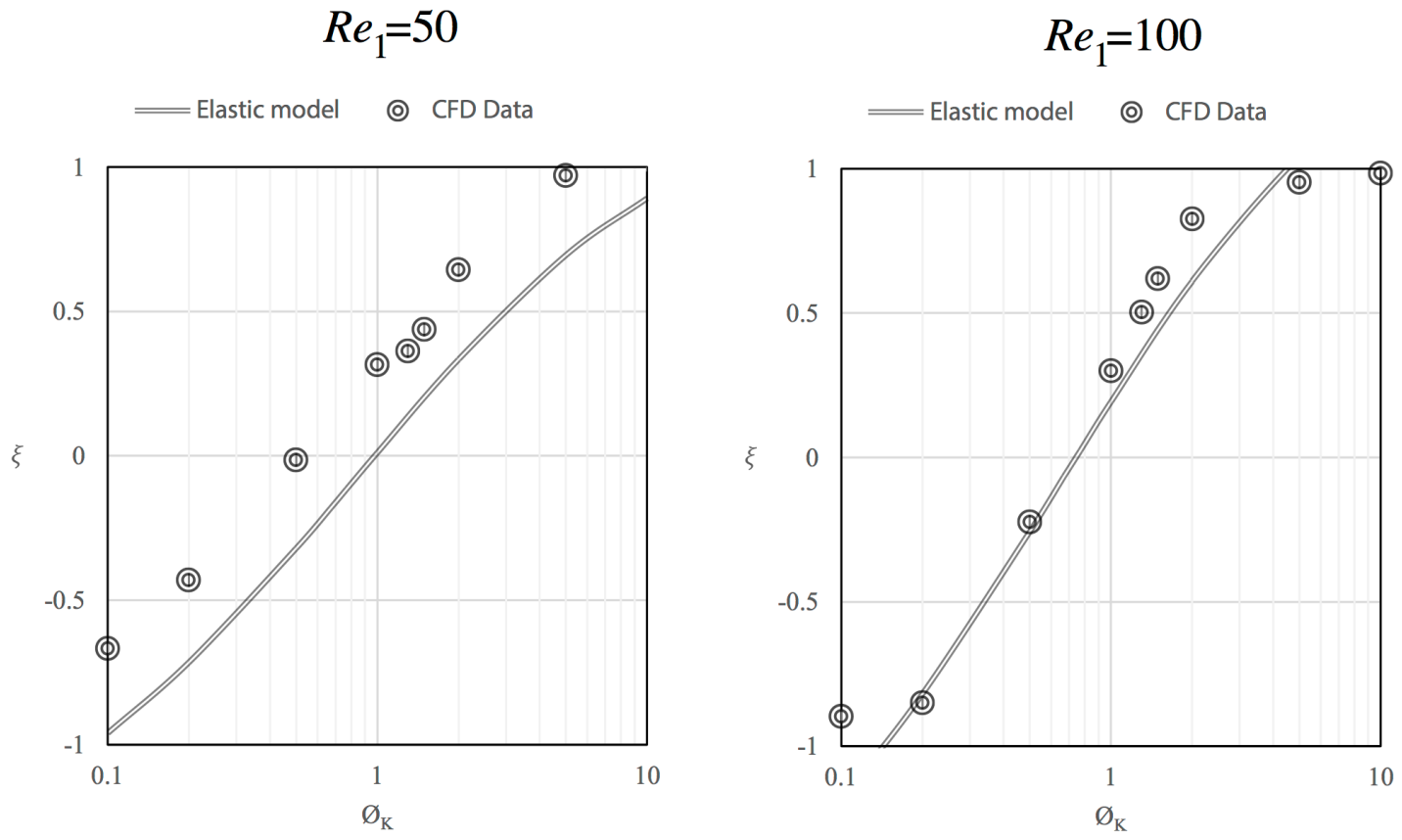

Figure 12 - Plot of jets impingement point displacement, $\xi$, from CFD simulation of fluids with viscosities $\mu_{1}=0.04 \mathrm{~Pa} \cdot \mathrm{s}$ and $\mu_{2}=0.02 \mathrm{~Pa} \cdot \mathrm{s}$ at $R e_{1}=50$ and $R e_{1}=100$. 


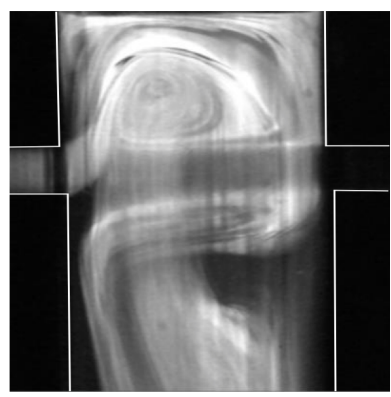

a)

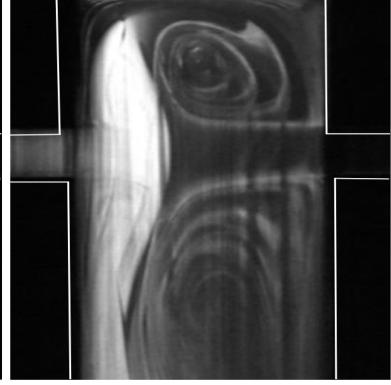

b)

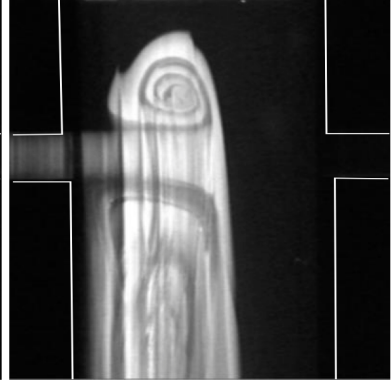

c)

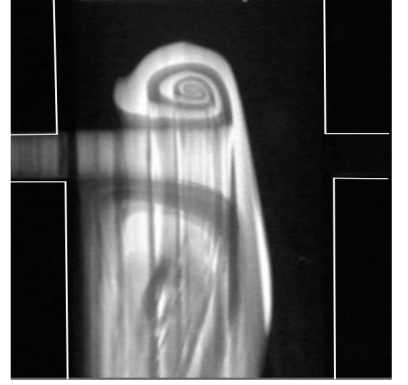

d)

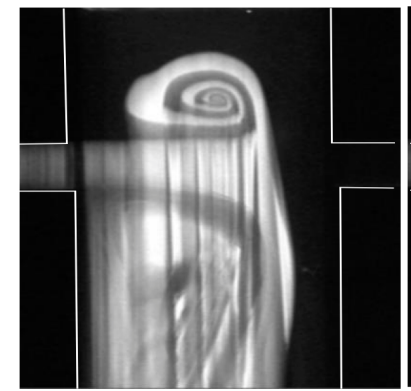

e)

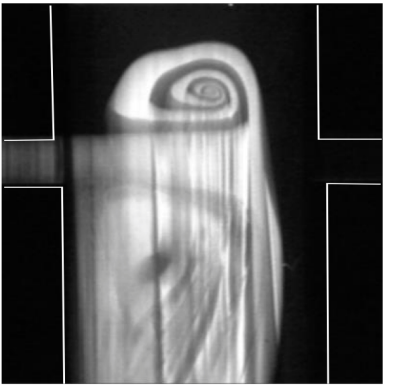

f)

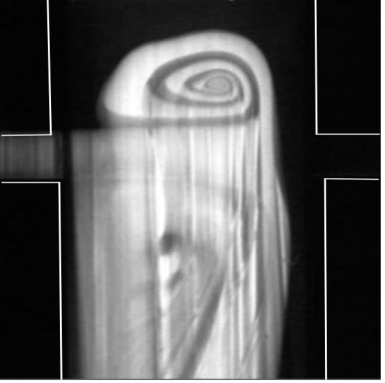

g)

Figure $13-\mathrm{PLIF}$ images of fluid $1, \mu_{1}=0.04 \mathrm{~Pa} \cdot \mathrm{s}$, and fluid $2, \mu_{2}=0.02 \mathrm{~Pa} \cdot \mathrm{s}$, for $R e_{1}=$ 50 and a) $\phi_{K}=0.1$, b) $\phi_{K}=0.2$, c) $\phi_{K}=0.5$, d) $\phi_{K}=1$, e) $\phi_{K}=2$, f) $\phi_{K}=5$ and g) $\phi_{K}=10$. 


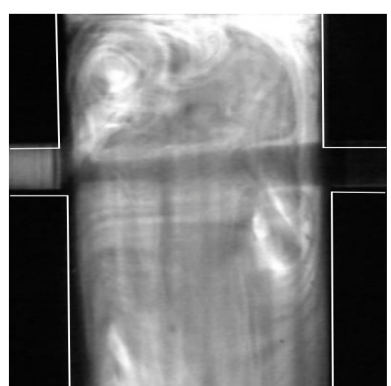

a)

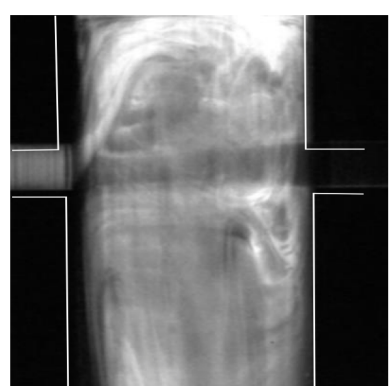

b)

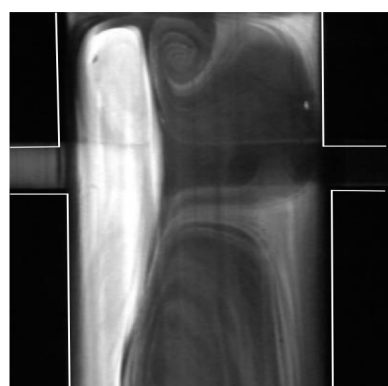

c)

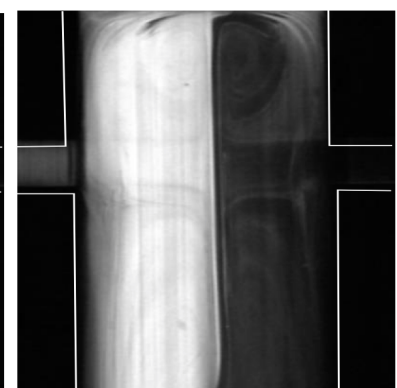

d)

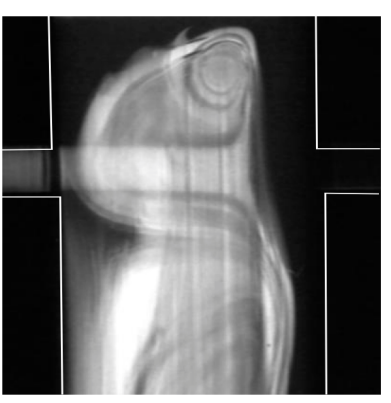

e)

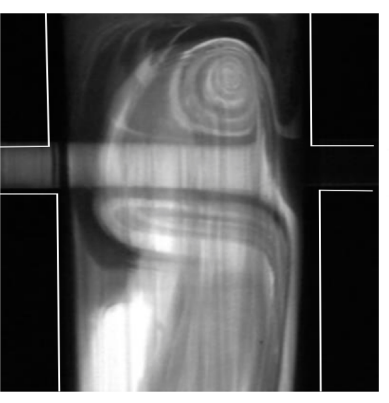

f)

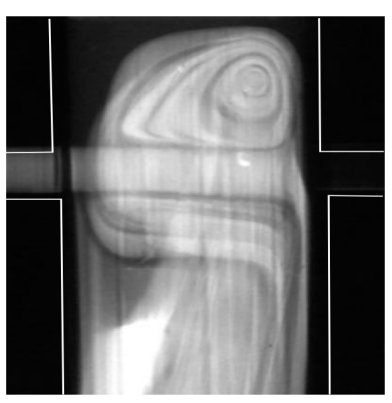

g)

Figure $14-\mathrm{PLIF}$ images of fluid $1, \mu_{1}=0.04 \mathrm{~Pa} \cdot \mathrm{s}$, and fluid $2, \mu_{2}=0.02 \mathrm{~Pa} \cdot \mathrm{s}$, for $R e_{1}=$ 100 and a) $\phi_{K}=0.1$, b) $\phi_{K}=0.2$, c) $\phi_{K}=0.5$, d) $\phi_{K}=1$, e) $\phi_{K}=2$, f) $\phi_{K}=5$ and g) $\phi_{K}=10$. 


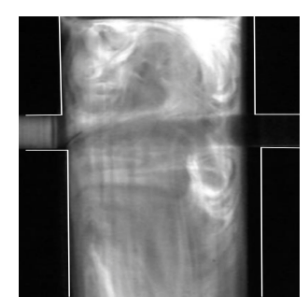

a)

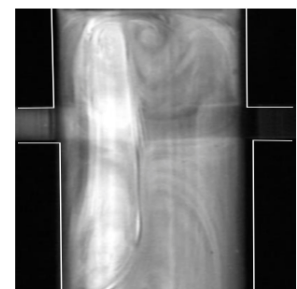

b)

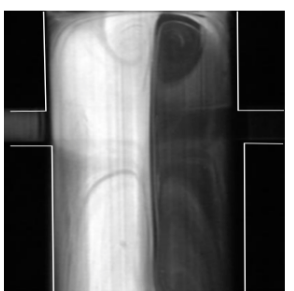

c)

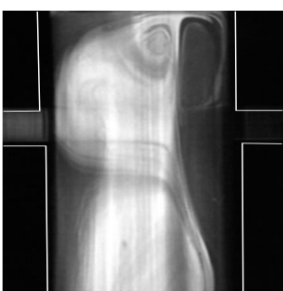

d)

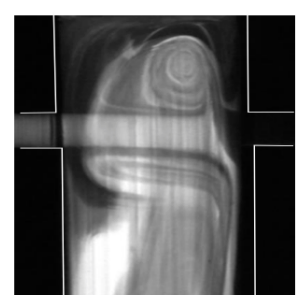

e)

Figure $15-\mathrm{PLIF}$ images of fluid $1, \mu_{1}=0.04 \mathrm{~Pa} \cdot \mathrm{s}$, and fluid $2, \mu_{2}=0.02 \mathrm{~Pa} \cdot \mathrm{s}$, for $\operatorname{Re}_{1}=$ 125 and a) $\phi_{K}=0.2$, b) $\phi_{K}=0.67$, c) $\phi_{K}=1$, d) $\phi_{K}=1.5$ and e) $\phi_{K}=5$. 


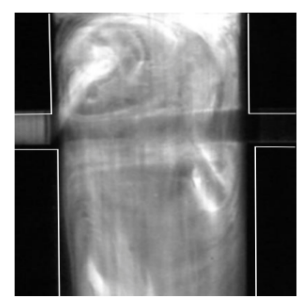

a)

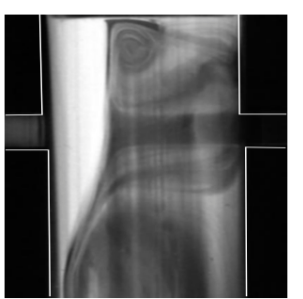

b)

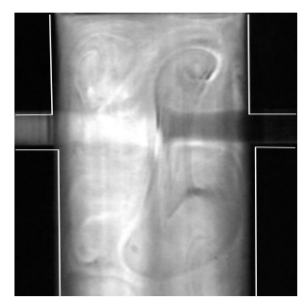

c)

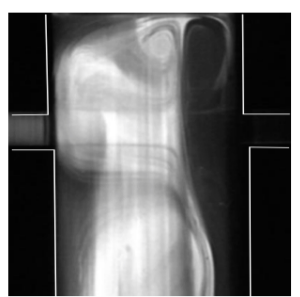

d)

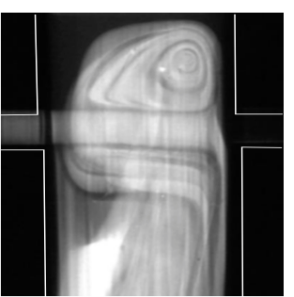

e)

Figure $16-\mathrm{PLIF}$ images of fluid $1, \mu_{1}=0.04 \mathrm{~Pa} \cdot \mathrm{s}$, and fluid $2, \mu_{2}=0.02 \mathrm{~Pa} \cdot \mathrm{s}$, for $R e_{1}=$ 150 and a) $\phi_{K}=0.2$, b) $\phi_{K}=0.5$, c) $\phi_{K}=1$, d) $\phi_{K}=1.5$ and e) $\phi_{K}=5$. 

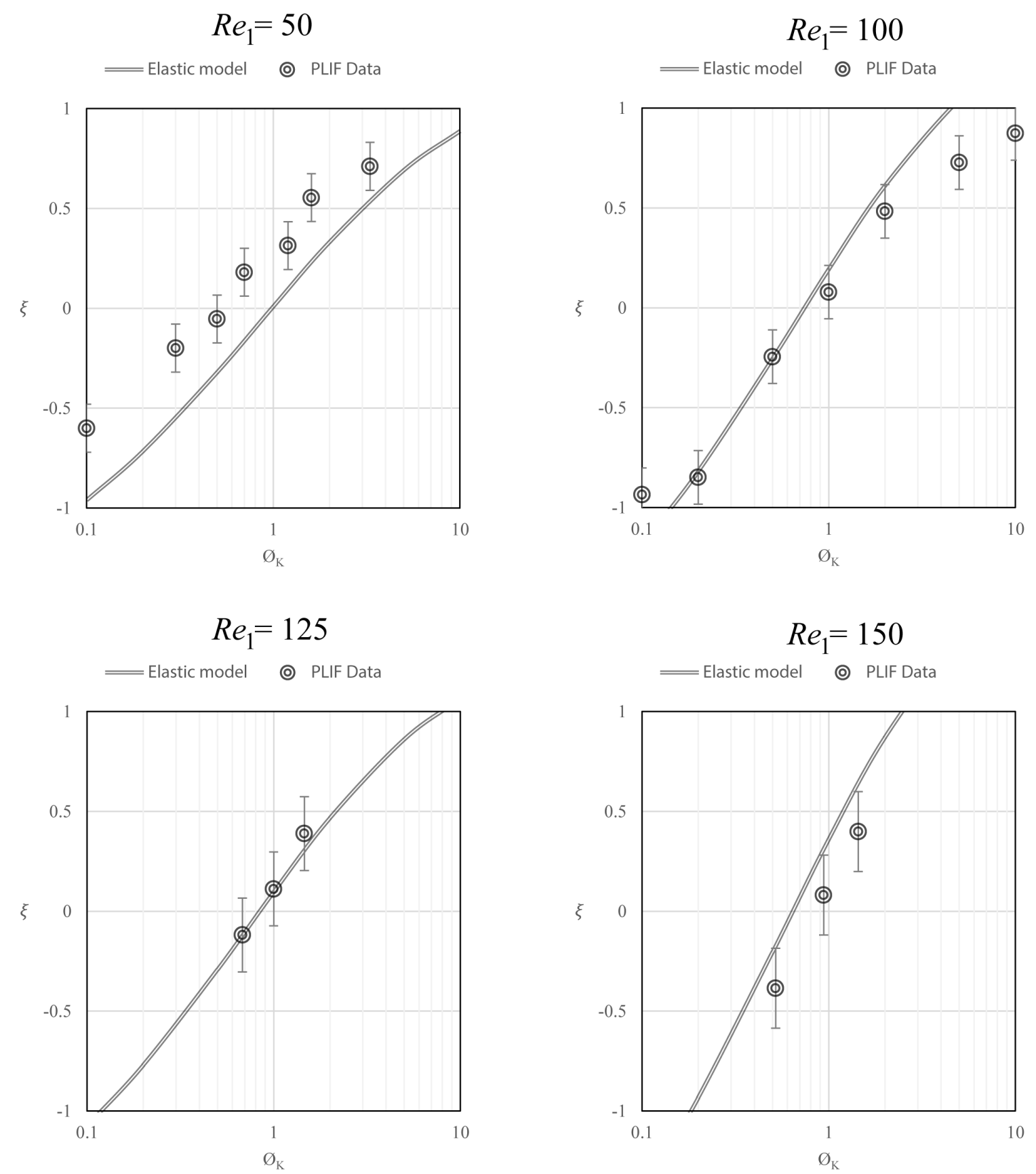

Figure 17 - Plot of jets impingement point displacement, $\xi$, from PLIF experiments for fluids with viscosities $\mu_{1}=0.04 \mathrm{~Pa} \cdot \mathrm{s}$ and $\mu_{2}=0.02 \mathrm{~Pa} \cdot \mathrm{s}$ at $R e_{1}=50, R e_{1}=100, R e_{1}=125$ and $R e_{1}=150$. 